\title{
Paper
}

\section{Study of a Teaching Method to Grow the Control Engineer of Precision} Apparatus

\author{
KAZUHIRO MORITA $^{* \dagger}$ Member, $\quad$ ShinjI WAKUI ${ }^{\ddagger}$ Non-member
}

(Received April 22, 2018, revised July 1, 2018)

\begin{abstract}
This paper proposes a teaching method and material to learn the control engineering in an industrial company. It is very important to teach engineers who have knowledge of control engineering in a company which is developing high precision equipment. However, there were not teaching curriculum and material that are suitable for beginner and intermediate engineers. Particularly, it is important the teaching material is low cost and linear system. Moreover, it is good to be the teaching material that is able to control with less programs. This paper proposes the one axis stage system that adopts Arduino ${ }^{\circledR}$ which is low-priced microcomputer for education and hobby. Arduino ${ }^{\circledR}$ is suitable for education of beginner and intermediate engineers because it can control peripheral devices with less programs. Then, engineers are not confused by making complicate programs. Therefore, engineers can learn the basics of control engineering surely because the one axis stage system is comprised of only linear elements. Here, even though the low-priced position sensor has a non-linear characteristic, it seems to be the linear sensor because it is linearized and encapsulated by Lagrange interpolation method. Engineers attending the lecture do not need to care non-linearity. This paper describes the one axis stage system and the teaching curriculum using the one axis stage. Then, this paper describes growing up of an engineer via developing of the active damping system. An engineer improved a repeatability of measurement accuracy of the LSI line width by developing of an active damping system.
\end{abstract}

Keywords: Engineer education, Feedback control, Linear system control, Lagrange interpolation, Active damper

\section{Introduction}

This chapter clarifies issue of teaching of control engineers. This paper argues teaching of engineers from the beginner to the intermediate level.

In late years, the high accuracy and high throughput of apparatus making semiconductor device are required by advances of smart phones, tablet PCs and IoT (Internet of Things). In addition, a demand of biochemistry inspection apparatus increases by population aging. In a company developing these apparatuses, speedup and high precision of the mechatronics are important. In such situation, the control engineering is the key technique to achieve positioning in nanometer order, highly precise temperature control, and highly precise damping vibration. Morita and Wakui have proposed precise apparatuses [1] [3]. Moreover, engineers who have skills to design and implement the control system are necessary. For a long time, many researchers have been studying the educational methods and equipment. Tasaki et al. developed educational tool in consideration of emotions [4]. Cheng et al. proposed a way of teaching control engineering using two-wheel mobile robot [5]. Canale and Casale-Brunet have proposed an education kit using the

\footnotetext{
* Corresponding Author: morita.fg@hitachi-hightech.com

$\dagger$ Hitachi High Technologies Corp.

882, Ichige, Hitachinaka-city, Ibaraki, 312-8504, Japan

$\doteqdot$ Tokyo University of Agriculture and Technology

2-24-16, Naka-cho, Koganei-shi, Tokyo, 184-8588, Japan
}

Lego ${ }^{\circledR}$ Mindstorms ${ }^{\circledR}$ for beginner [6]. Hoshino, Yamakita and Furuta have also proposed an apparatus which is the inverted pendulum for education of the control engineering [7]. Park has proposed a jumping ring system as an educational tool [8]. Authors and companies have been trying to teach control engineers in accordance with these researches. However, the teaching has not gone well. As a result of study, the differences between the education in university and the teaching in the industry were found. In the university, the lecturer should consider the lecture that students can be interested in. Furthermore, researcher are interested in the control of complex object. Thus, unstable and complex object was chosen as the teaching material. The inverted pendulum was used in many research. However, it was not suitable for the teaching in the industry. It becomes difficult for the engineers to understand mechanism and the control theory exactly, when the lecturer uses the unstable controlled object. Furthermore, the unstable object is hard to understand and the complicated even though it is delightfulness for students. The interesting mechanism is not necessary because engineers in the industry have enough motivation. For those reasons, the lecture to beginner and intermediate engineers was complicated, and the understanding level of them was not raised.

Then, the teaching materials of the control engineering are expensive. There are experimental equipment on the teaching tool market. They are able to control flow quan- 


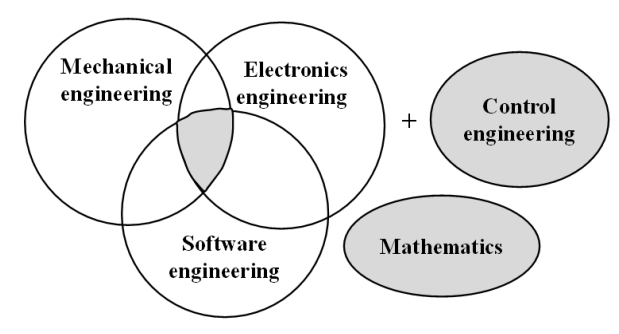

Figure 1: A technical area that the control engineer should be learned.

tity and temperature precisely [9] [10]. They were used for the control experiments using the PID control, the fuzzy control, the modern control and the advanced control [11]. However, they are expensive even though they are precisely and usefully. On the other hand, Manabe has proposed a low cost experimental equipment [12]. However, it was an inverted pendulum which is non-stable and non-linear system. Therefore, it was not able to introduce into the beginner class.

In addition, engineers learning the control engineering need much related knowledge, even though they want to learn only the essence of the control engineering. Engineers need skills of making programs which run in a microcomputer even if their specialty are mechanical and electronics. It is also not easy to develop the microcomputer substrate and peripherals. There is a method using Arduino ${ }^{\circledR}$ to reduce such burden. Several researcher and teacher have tried to develop easy and low cost teaching material using Arduino $^{\circledR}$. Rubio et al. have developed basic experimental material using Arduino ${ }^{\circledR}$ [13]. However, it was difficult to teach the control engineering because its purpose of the system was only learning of programming. Luiz et al. and Araújo et al. have each proposed educational robotics kits using it in high school [14] [15]. However, these kits were not able to teach the control engineering because they have been focused to a learning of programming. Moreover, they have been focused to only the open loop control. There is the Raspberry $\mathrm{Pi}^{\circledR}$ that is similar to Arduino ${ }^{\circledR}$. Hoyo et al. have proposed a teaching method using the Raspberry $\mathrm{Pi}^{\circledR}$ [16]. However, it has not had interest in modeling of controlled object. Even though Zhong and Liang have also proposed a teaching kit using the Raspberry $\mathrm{Pi}^{\circledR}$, it was focused to teaching the IoT [17]. For such reasons, it was difficult to teach the feedback control engineering using these proposes.

Therefore, a purpose of this paper is the proposing a teaching method of the control engineer developing the precision apparatus. This paper is constituted by four sections. In the first section, this paper proposes the one axis stage system as a teaching material which is low cost and is stable and is constituted by only linear and simple elements. Engineers can control the one axis stage by lesser program and only basic control technique. In the second section, this paper proposes the teaching curriculum using the one axis stage system. In the third section, this paper describes a result of an experimental lecture using the one axis stage. In

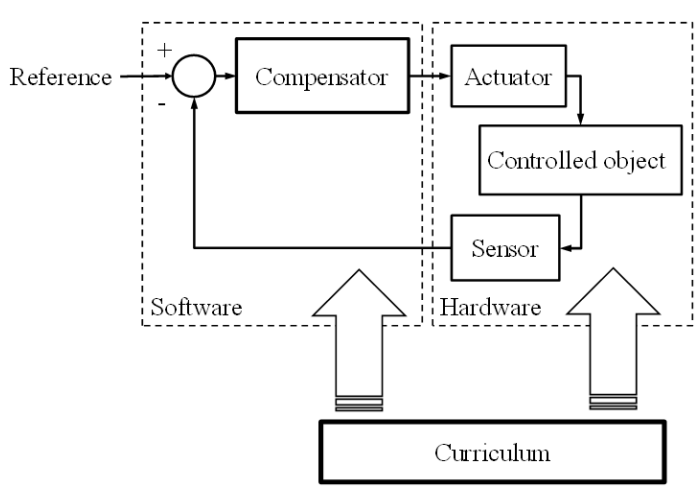

Figure 2: A schematic of the education of control engineering.

the fourth section, this paper describes a result of development of an active damping system which was designed by an engineer who learned in proposed curriculum.

\section{Teaching Material}

This chapter shows requirements about teaching of the control engineering. Then, it proposes a teaching equipment suitable for engineer education.

2.1 Requirements Fig. 1 shows the area that control engineers should learn. Engineers of the control engineering need to know the basic knowledge of mechanical engineering to understand a controlled object. Furthermore, they need the basic knowledge of electronics engineering to understand actuators and sensors. In addition, they should have the basic knowledge of software engineering to understand and implement compensators. Furthermore, mathematics such as linear algebra and calculus is necessary as the tool to understand the principle and analyse the system. The engineers should learn various control engineering based on these knowledge. In this way, the engineers should get both of wide related knowledge and deep special skill. The company should grow such engineers in short term. Therefore, the experience based teaching using real controlled object is often adopted in the lecture of the control engineering.

Fig. 2 shows a goal of teaching method in this study. Its diagram is configured by three items which are the hardware part, the software part and the curriculum. The hardware part is constituted by an actuator, a sensor and a mechanical object. It is important to provide simple hardware that is stable and linear. The software part is constituted by microcomputer substrate and some programs. It is important to provide the environment that is able to make programs easily. Then, the curriculum combines the hardware and the software part. Particularly, it is important to provide the curriculum that is suitable to learn the control engineering.

Fig. 3 shows detail of the software part that is a digital compensator. The compensator is made up of a microcomputer, peripheral devices and software. Peripheral devices include a periodic timer, a D/A converter and an A/D converter. The software is comprised of programs that are used for a $\mathrm{D} / \mathrm{A}$ conversion, an A/D conversion, generation of pe- 


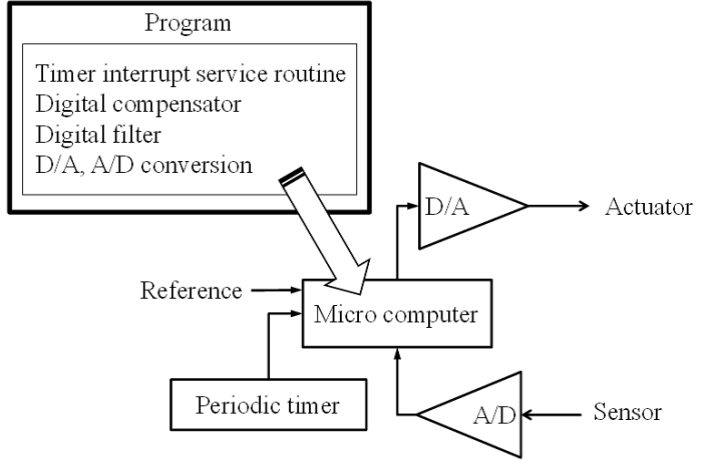

Figure 3: Components of the digital compensator.

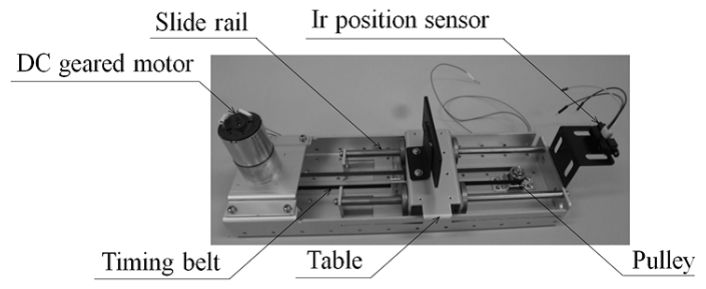

Figure 4: Mechanism of the one axis stage.

riodic cycle, and compensation. The most of recent control engineering are realized by the discrete control using a microcomputer and the DSP (Digital Signal Processor). This paper proposes the teaching material based on such background.

2.2 1-Axis Positioning Stage This section proposes the controlled object. It is easy to understand principle and mechanism as a teaching material. The one axis positioning stage was chosen as a teaching material of control engineering. It was considered that the stage was stable and linear system. Fig. 4 shows the one axis stage which was developed for teaching. Here, the Ir means infrared ray. It is controlled by a DC motor, pulley mechanism and a distance sensor. The stage system uses a slide rail as slide mechanism. The DC motor with a built-in gear is adopted to actuate the stage system, and adopted infrared rays-type distance sensor to measure a position of the table. The table fixing to the pulley moves straight along a slide rail. It is driven by the DC motor via the pulley. The distance sensor measures the distance between the table and the stage end where a sensor was placed. Feedback control of this system is implemented in three steps. At the first step, a microcomputer gets a position of the table that is measured by a distance sensor via an A/D converter. At the second step, the microcomputer calculates the actuating variable based on position error. At the third step, the microcomputer outputs the actuating variable to the DC motor via the PWM (Pulse Width Modulation) circuit. The microcomputer repeats these steps periodically. Herewith, feedback control system was made with small, lightweight, simple, and low cost. Table 1 shows specifications of it. It is suitable for the teaching material because lecturer can prepare enough it easily.
Table 1: Specifications of 1-axis stage.

\begin{tabular}{ccc}
\hline Item & Specification & Remarks \\
\hline Guide type & Linear shaft $/$ & - \\
linear bush & \\
Feed mechanism & Timing pulley & - \\
Stroke & $150 \mathrm{~mm}$ & $60 \sim 210 \mathrm{~mm}$ \\
Weight & $0.65 \mathrm{~kg}$ & - \\
DC motor gear ratio & $75: 1$ & - \\
Ir distance sensor output & $0.4 \sim 2.3 \mathrm{~V}$ & $100 \sim 800 \mathrm{~mm}$ \\
\hline
\end{tabular}

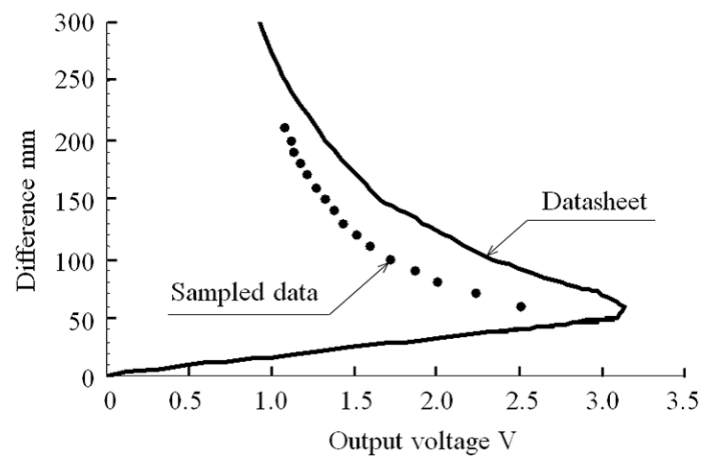

Figure 5: Characteristics of a distance sensor.

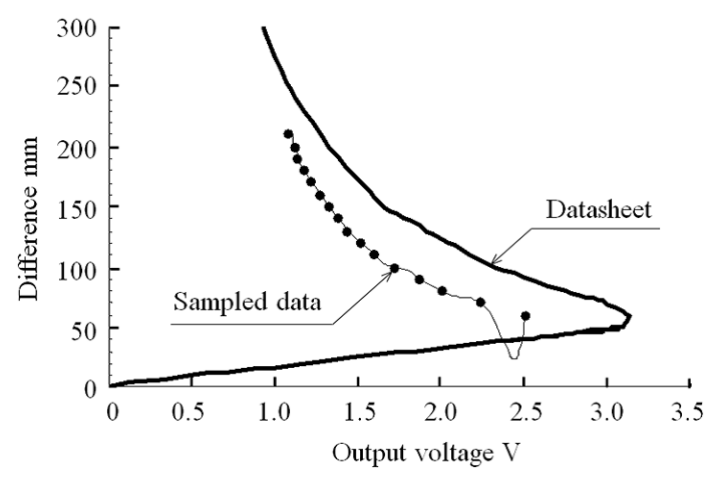

Figure 6: Result of Lagrange interpolation (the 8th).

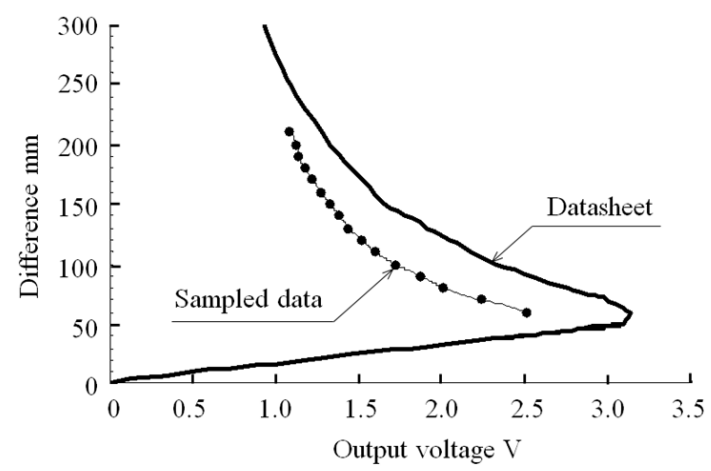

Figure 7: Result of Lagrange interpolation (moving and the 3rd).

2.3 Interpolating of Distance Sensor This section describes an interpolation of a distance sensor by Langrange interpolation method. Fig. 5 shows characteristics of a distance sensor which is adopted in this study. There are two profiles in Fig. 5. They are a datasheet and an actual mea- 
surement. An actual measurement data are measured as output voltage every $10 \mathrm{~mm}$ between $210 \mathrm{~mm}$ from $60 \mathrm{~mm}$ which is the movable area of the one axis stage. According to a datasheet, the output voltage for the distance shows a non-linear characteristic. The actual measurement shows a tendency same as the datasheet, even if there is the offset voltage. Therefore, a position of the one axis stage can measure by measuring the output voltage of a distance sensor. However, a non-linear characteristics cannot handle as a proportional element. Hence, its characteristics should be encapsulated as the linear element by Lagrange interpolation method. Engineers attending a lecture can ignore a non-linear characteristics. It is easy to calculate Lagrange interpolation method in a real time because computational complexity is small. Equations (1), (2) show the interpolation method. Here, $y\left(v_{0}\right), y\left(v_{1}\right), y\left(v_{2}\right), \cdots, y\left(v_{n}\right)$ for $v_{0}, v_{1}, v_{2}, \cdots, v_{n}$ are already known. Herewith, $y_{p}(v)$ for any $v$ can calculate by the interpolation.

$$
\begin{aligned}
& y_{p}(v)=\sum_{j=0}^{n} y\left(v_{j}\right) g_{j}(v) \\
& g_{j}(v)=\prod_{\substack{0 \leq k \leq n \\
k \neq j}} \frac{v-v_{k}}{v_{j}-v_{k}} \\
& =\frac{\left(v-v_{0}\right)\left(v-v_{1}\right) \cdots\left(v-v_{j-1}\right)\left(v-v_{j+1}\right)\left(v-v_{n}\right)}{\left(v_{j}-v_{0}\right)\left(v_{j}-v_{1}\right) \cdots\left(v_{j}-v_{j-1}\right)\left(v_{j}-v_{j+1}\right)\left(v_{j}-v_{n}\right)}
\end{aligned}
$$

Fig. 6 shows the result of interpolating for actual measurement data by Lagrange interpolation of the eighth. According to Lagrange interpolation method, it is theoretically possible to interpolate the fifteenth from sixteen points of actual measurement data. However, high order interpolation should be handled carefully. By increasing an order, the vibration that is called Runge's phenomenon may appear. In Fig. 6, vibration due to Runge's phenomenon is already seen in the interpolation of the eighth. Therefore, it cannot apply to measurement data.

A way to solve above mentioned problem was studied. It has two procedures. At the first step, four actual measurement data are chosen. When a measured output voltage $\mathrm{v}$ is in range of $\left[v_{i}, v_{i+1}\right]$, four data $\left(v_{i-1}, y\left(v_{i-1}\right)\right),\left(v_{i}, y\left(v_{i}\right)\right),\left(v_{i+1}, y\left(v_{i+1}\right)\right),\left(v_{i+2}, y\left(v_{i+2}\right)\right)$ are chose. At the second step, Lagrange interpolation of the third is applied to four data. Then, the position $y(v)$ is calculated by Lagrange interpolation of the third. Here, $y\left(v_{i}\right)$ $\mathrm{mm}$ is actual measured position data of the one axis stage when the output voltage is $v_{i}$ V. Program calculating the interpolation can make easily because Lagrange interpolation of the third can express as equation (3). Fig. 7 shows a result of the interpolation using Lagrange interpolation method of the third with selecting data. It can interpolate smoothly in

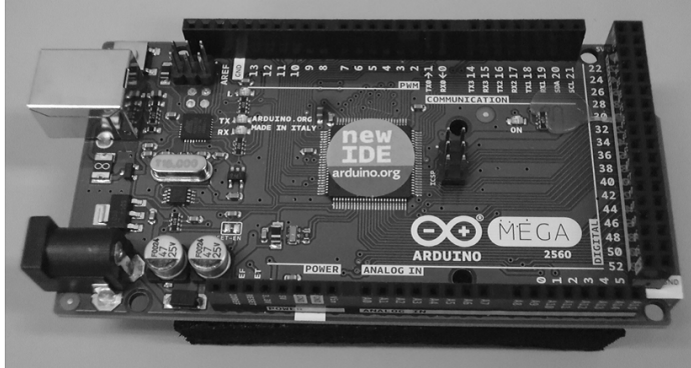

(a) Arduino ${ }^{\circledR}$ MEGA 2560

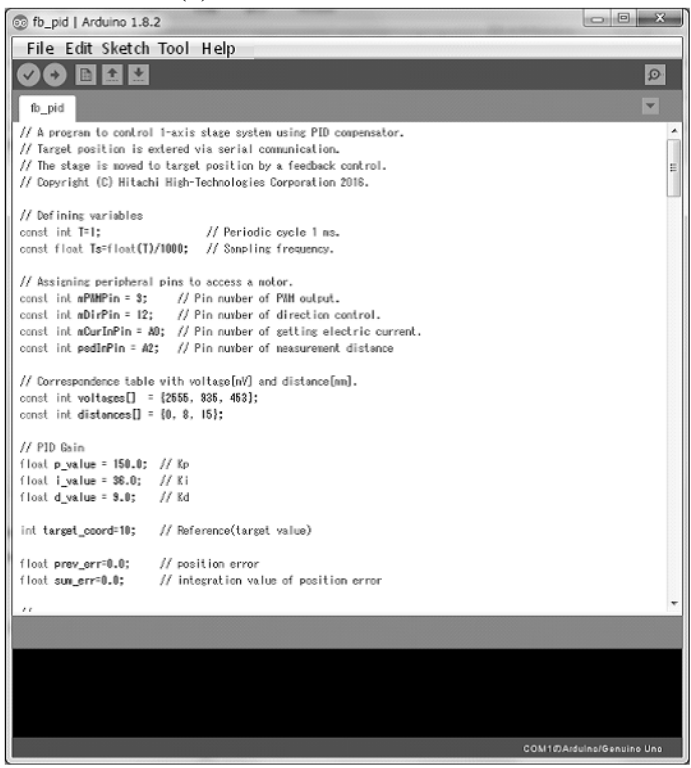

(b) Screenshot of IDE

Figure 8: Hardware and Software of the Adcuino ${ }^{\circledR}$.

whole of movable area

$$
\begin{aligned}
y(v) & =y\left(v_{i-1}\right) \frac{\left(v-v_{i}\right)\left(v-v_{i+1}\right)\left(v-v_{i+2}\right)}{\left(v_{i-1}-v_{i}\right)\left(v_{i-1}-v_{i+1}\right)\left(v_{i-1}-v_{i+2}\right)} \\
& +y\left(v_{i}\right) \frac{\left(v-v_{i-1}\right)\left(v-v_{i+1}\right)(v-v i+2)}{\left(v_{i}-v_{i-1}\right)\left(v_{i}-v i+1\right)\left(v_{i}-v i+2\right)} \\
& +y\left(v_{i+1}\right) \frac{\left(v-v_{i-1}\right)\left(v-v_{i}\right)\left(v-v_{i+2}\right)}{\left(v_{i+1}-v_{i-1}\right)\left(v_{i+1}-v_{i}\right)\left(v_{i+1}-v_{i+2}\right)} \\
& +y\left(v_{i+2}\right) \frac{\left(v-v_{i-1}\right)\left(v-v_{i}\right)\left(v-v_{i+1}\right)}{\left(v_{i+2}-v_{i-1}\right)\left(v_{i+2}-v_{i}\right)\left(v_{i+2}-v_{i+1}\right)}
\end{aligned}
$$

2.4 Arduino ${ }^{\circledR}$ microcomputer and Scilab Arduino ${ }^{\circledR}$ was chosen as a microcomputer. Arduino ${ }^{\circledR}$ is commercial small microcomputer [18]. It was adopted in this study because the educational effect and the cost balance in this study. In addition, Arduino ${ }^{\circledR}$ can cooperate with Scilab that is an OSS (Open Source Software) used for numerical simulation [19]. Moreover, a cooperation with Scilab is useful in product development because Scilab is used frequently for research and development of control engineering. Fig. 8(a) shows Arduino ${ }^{\circledR}$, and Fig. 8(b) shows a screenshot of the IDE (Integrated Development Environment). Arduino ${ }^{\circledR}$ was developed for an education use and a hobby. It is integrating in a single board with a microcomputer and peripherals which are digital I/Os, A/D converters, PWM outputs and functional timers. 


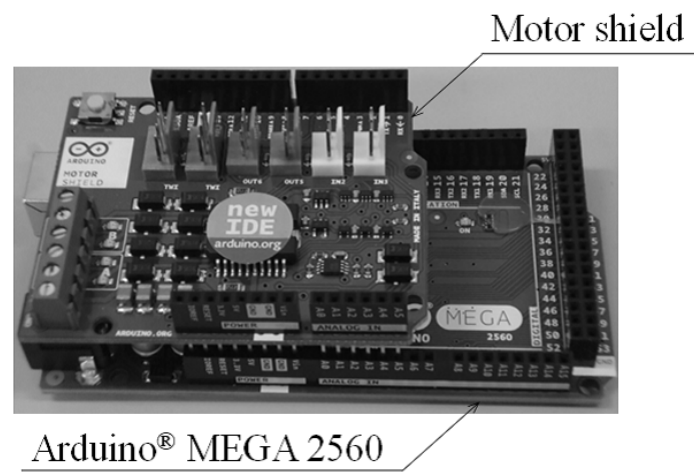

Figure 9: Photograph of the motor shield with Adcuino ${ }^{\circledR}$.

It can easily use bus power of the USB as the power supply. On the other hand, Arduino ${ }^{\circledR}$ can use an external power supply when a system drives the actuator using big electricity. In addition, Arduino ${ }^{\circledR}$ can connect with peripheral devices easily because I/O pins are implemented beforehand. Since Arduino ${ }^{\circledR}$ has useful IDE, it can develop software and install a software into flash memory very easily. Fig. 8(b) shows that it is simple and easy to operate the IDE. Furthermore, it has ingenuity to make a program easily. Programmer can make a program by calling simply API (Application Program Interface) without knowing hardware details and mechanism because a periodic timer, a PWM, an A/D conversion and a D/A conversion control functionality are encapsulated as a library. Furthermore, compatible various optional boards called the shield are released. The shield has common I/O pins layout, and it is extended by just connecting the shield as a daughter to a microcomputer board. In this study, the motor shield was adopted to drive a motor. Fig. 9 shows a combination with Arduino ${ }^{\circledR}$ MEGA 2560 and the motor shield.

Several kinds of Arduino ${ }^{\circledR}$ series products are sold by memory size, CPU, and number of peripherals. Even though the $\mathrm{AVR}^{\circledR}$ is adopted as CPU, engineers do not need to know kind of the CPU due to superior IDE and good compatible interface design. Even though Arduino ${ }^{\circledR}$ Uno is used for beginner use well [14] [15], SRAM memory of 2 $\mathrm{kB}$ is insufficient for teaching materials of control engineering. Large memory is often necessary to collect chronological order data. Therefore, Arduino ${ }^{\circledR}$ MEGA 2560 was adopted in this study because it has SRAM memory of 8 $\mathrm{kB}$. Arduino ${ }^{\circledR}$ DUE is not suitable for teaching material even though it has SRAM of $96 \mathrm{kB}$. Because Scilab cannot connect to Arduino ${ }^{\circledR}$ DUE. Voltage of power supply is different of Arduino ${ }^{\circledR}$ MEGA and Arduino ${ }^{\circledR}$ DUE, because Aruduino ${ }^{\circledR}$ DUE adopts the ARM processor. Therefore, Arduino ${ }^{\circledR}$ MEGA 2560 cannot share some kinds of the shields with Arduino ${ }^{\circledR}$ DUE.

Making and reading complicated programs will be a burden on engineers attending a lecture. They will lose willingness to learn control engineering. In this respect, Arduino ${ }^{\circledR}$ is convenient. In the IDE, source program is called the sketch. The sketch is based on C-language, but the main( ) is not necessary. The sketch is constituted by two functions which are called setup( ) and $\operatorname{loop}($ ). The setup( ) is used for

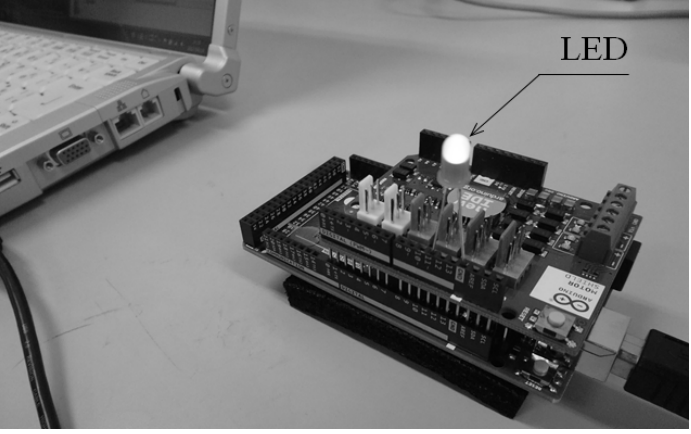

(a) Experimental equipment

/// Program to blink an external LED.

// This is a program to blink an external LED in 0.5 second periodic cycle. // Caution: Connect a LED to pin of number 11

// Copyright $(\mathrm{C})$ Hitachi High-Technologies Corporation 2016

const int blink=LOW; // Defining a variable to blink a LED

// The setup 0 is executed just once at startup.

void setup 0\{

pinMode(11, OUTPUT); // Pin -11 is assigned as an digital output mode. \}

// The loop()is executed repeatedly forever

void loop ()

if ( blink==LOW ) // Inversion of status of a LED

blink = HIGH; // Changing status from LOW to HIGH(Turning on a LED). else

blink=LOW; // Changing status from HIGH to LOW(Turning offa LED).

digitalWrite(11, blink); // Outputting status to the Pin-11.

delay $(500)$; / Wait for $500 \mathrm{~ms}$ \}

(b) Example of a sketch

Figure 10: Experiment of the LED blinking.

hardware setting up. It is executed only one time at startup. The loop( ) is used for executing periodic procedure. It repeats itself automatically and periodically. Program which calculates a compensation is executed in the loop( ). Engineers can make programs to access hardware easily using prepared software library. There are the software library to control hardware such as a D/A, an A/D and a PWM. Fig. 10(a) and (b) show an experiment material to blink a LED. Former shows an experimental equipment which attached a LED to Arduino ${ }^{\circledR}$. Latter shows an example sketch to blink a LED. The delay (500) of the last line means waiting time and the control period of 500 milliseconds.

2.5 Curriculum This section describes a curriculum to teach control engineering. Table 2 shows the summary of the curriculum for beginners. It covers overall the classical control theory. Engineers learn from basic knowledge of microcomputer to PID control.

By the first lecture, engineers understand how to control a LED connecting to a digital I/O port of a microcomputer. Then, engineers become able to make a program to control LED. In addition, engineers attending the lecture have experience related to the frequency domain by connecting a LED to a PWM port and getting an experience about the $1 / f$ fluctuation of a LED.

By the second lecture, engineers understand a way to measure position. They understand relationship between a distance sensor and an analog input port of a microcom- 
Table 2: Summary of the education curriculum.

\begin{tabular}{|c|c|c|}
\hline No. & Contents & Description \\
\hline 1 & $\begin{array}{l}\text { LED blinking } \\
\text { control }\end{array}$ & $\begin{array}{l}\text { Understand of Arduino }{ }^{(\mathbb{R})} \text { and } \\
\text { basics of hardware control. }\end{array}$ \\
\hline 2 & $\begin{array}{l}\text { Measurement } \\
\text { with position } \\
\text { sensor }\end{array}$ & $\begin{array}{l}\text { Understand the measurement of } \\
\text { position with the Ir distance } \\
\text { sensor. }\end{array}$ \\
\hline 3 & Motor control & $\begin{array}{l}\text { Understand basics of PWM } \\
\text { control. }\end{array}$ \\
\hline 4 & Speed control & $\begin{array}{l}\text { Understand motor speed } \\
\text { changes depending on } \\
\text { a distance sensor. }\end{array}$ \\
\hline 5 & $\begin{array}{l}\text { Time response } \\
\text { and frequency } \\
\text { response }\end{array}$ & $\begin{array}{l}\text { Understand the interconversion } \\
\text { with time domain and } \\
\text { frequency domain. }\end{array}$ \\
\hline 6 & $\begin{array}{l}\text { Feedback } \\
\text { control }\end{array}$ & $\begin{array}{l}\text { Understand an effect of } \\
\text { feedback with only proportional } \\
\text { compensator. }\end{array}$ \\
\hline 7 & PID control & $\begin{array}{l}\text { Understand an effect of } \\
\text { feedback with a PID } \\
\text { compensator. }\end{array}$ \\
\hline
\end{tabular}

puter. Then, they understand a way to measure position by making a program.

By the third lecture, engineers understand a way to control speed of a motor by real experience. They use PWM function that Arduino ${ }^{\circledR}$ provides to control speed. The motor shield is combined with Arduino ${ }^{\circledR}$ to drive a motor. In this experiment, engineers change rotary direction of a motor by a serial communication function integrating into the IDE.

By the fourth lecture, engineers learn a concept of the feedback control by real experience of changing motor speed. The speed is changing by output of a distance sensor. In this experiment, engineers feel the realization that revolution speed of a motor is linking to a distance sensor by simply program.

By the fifth lecture, engineers find a model of controlled object as a transfer function. At first, engineers measure a step response of the one axis stage. Then, engineers identify stage properties for a transfer function using Scilab. Afterwards, engineers understand a concept of the model based development. In addition, they understand that a control simulation is easy.

By the sixth lecture, engineers understand effect and stability of a feedback control system using only a proportional compensator. Then, engineers understand effect of the compensator more deeply by comparing it with a result of simulation.

By the seventh lecture, engineers understand effect of PID compensator by comparing it with a proportional compensator. Moreover, they learn a method to make a discrete compensator. Since Scilab provides a toolbox to connect to the Arduino ${ }^{\circledR}$, cooperation of them is very easy. Furthermore, engineers make easily the HILS (Hardware In the Loop Simulation) environment using Scilab and the Arduino $^{\circledR}[15]$.

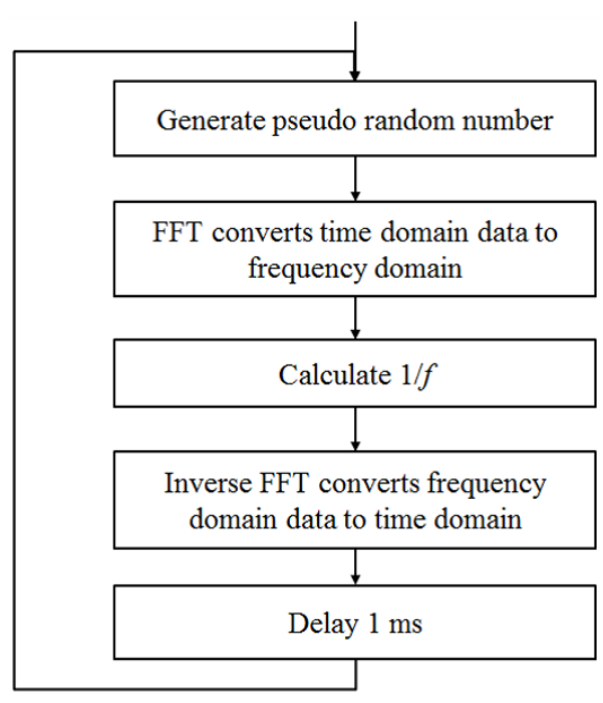

Figure 11: Flowchart of $1 / f$ fluctuation.

\section{Experiments}

This chapter shows three kind of experiments. At the first, an experiment of an LED fluctuation is shown. At the second, an experiment of feedback control using the one axis stage is described. Finally, an experiment of the active damping system is shown. An engineer who attended new curriculum has developed the active damping system.

3.1 $1 / f$ Fluctuation This section shows the $1 / f$ fluctuation of LED blinking. It is a part of new curriculum. Engineers attending new curriculum learn basics of a microcomputer system and a design method of frequency domain via this experiment.

As well as known, there are a lot of $1 / f$ fluctuations in the natural world. For example, there are the noise of the electronic circuit, rustling the wind, the annual ring of the tree, and a heartbeat. In addition, the healing effect of the $1 / f$ fluctuation is known. The application of the $1 / f$ fluctuation is increasing. However, the theoretical understanding of the $1 / f$ fluctuation is difficult for beginner engineers. Then, simply method to learn frequency domain was prepared. Engineers learn frequency domain through the $1 / f$ fluctuation. Fig. 11 shows a flowchart to fluctuate a LED. As the first step, microcomputer generates 4,096 pseudo random numbers. Fig. 12(a) shows generated numbers. At the second step, a microcomputer converts time domain data to frequency domain data by FFT. Fig. 12(b) shows its frequency characteristics. It is white noise. At the third step, the $1 / f$ filter multiplies $1 / 1,1 / 2,1 / 3, \cdots, 1 / 4096$ by the amplitude every frequency. Fig. 12(c) shows a result of calculating $1 / f$ with fitted curve. Engineers understand that it is $1 / f$ characteristic. At the final step, microcomputer reconverts frequency domain data to time domain data by inverse FFT. Fig. 12(d) shows converted time domain data. Engineers understand that it is fluctuating by comparison with Fig. 12(a). A microcomputer outputs time domain data in Fig. 12(d) to analogue output port.

3.2 Feedback Control of The One Axis Stage The control engineering was taught using proposed curriculum 


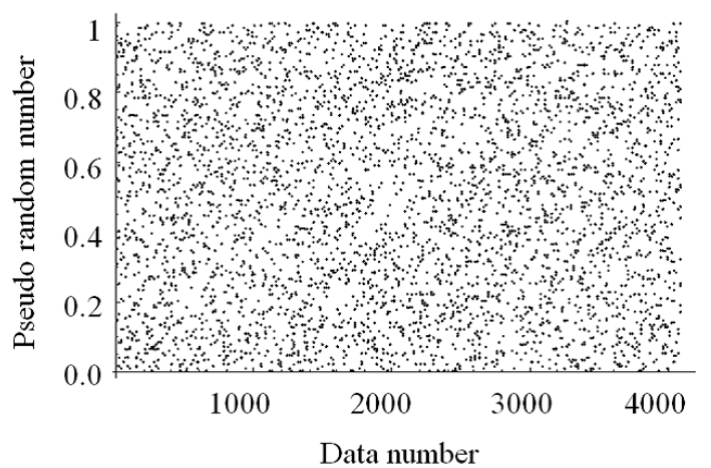

(a) Generated pseudo random number

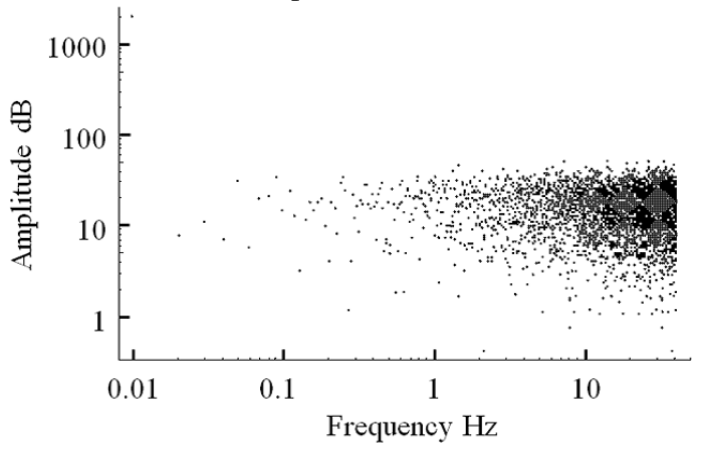

(b) Result of FFT

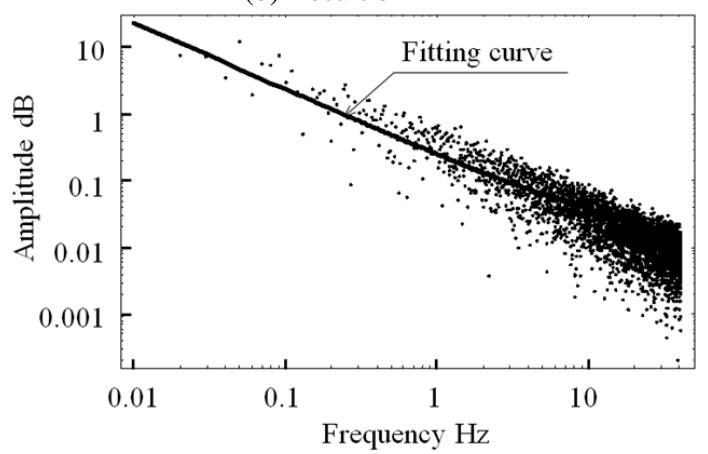

(c) $1 / f$ multiplying

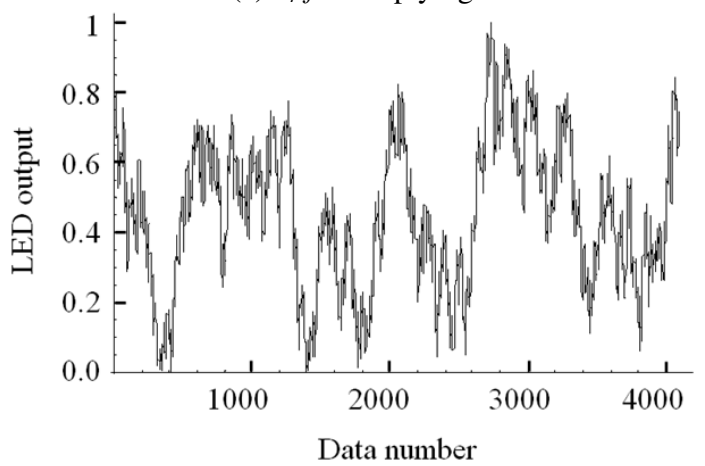

(d) Result of inverse FFT

Figure 12: $1 / f$ filter.

to beginner. An experiment has compared understanding of engineers who have attended lecture by two curriculums. Engineers in the first group learned the control engineering by conventional curriculum. Conventional one was configured by a lecture and some numerical simulations. Engineers in the second group learned by new curriculum. New one is appending practical training using the one axis stage
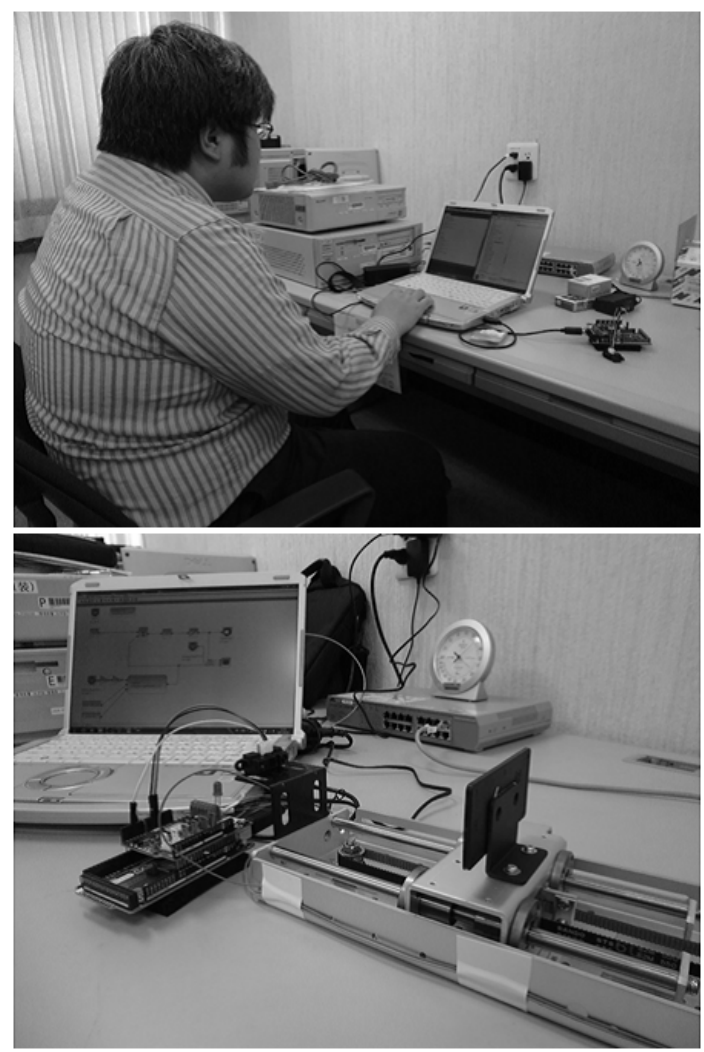

Figure 13: Situation of the feedback control experiment.

system to the conventional curriculum. Fig. 13 shows a situation of a control experiment of the second group. The engineer is measuring a step response to get a model of the one axis stage. Equation (4) shows a transfer function $G_{p}(s)$ based on a measurement data. Scilab is useful to calculate a transfer function. Here, $s$ is Laplace operator. The $G_{p}(s)$ consists of the third order transfer function and a dead time element. The characteristic of the $G_{p}(s)$ corresponds with the one of the one axis stage. It is constituted by a dead time element, the first lag element and the second lag element. Response delay of the pulley mechanism makes a dead time element. A DC motor makes the first lag element. A table with a slide rail makes the second lag element.

$$
G_{p}(s)=e^{-0.127 s} \frac{0.1011 s^{2}+2.471 s+131.3}{s^{3}+29.19 s^{2}+1153 s+848.2}
$$

Fig. 14 shows a comparison between a measurement step response and a simulation one. They are almost same.

In this way, engineers understand that a control simulation is easy by Scilab, if engineers found a model of controlled system. Fig. 15 shows the block diagram that is including the controlled object and a compensator. Fig. 16 shows a feedback simulation result of the step response by Scilab.

Fig. 17(a) shows a result of feedback control of the one axis stage. An engineer who attended new curriculum has designed its compensator. According to Fig. 17(b) which is close up of Fig. 17(a), smooth positioning without an overshoot is confirmed. Positioning accuracy is $\pm 100 \mu \mathrm{m}$. The 


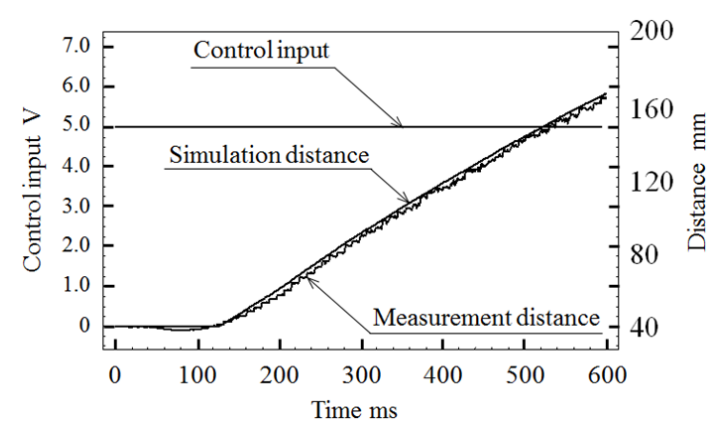

Figure 14: Measurement of a step response.

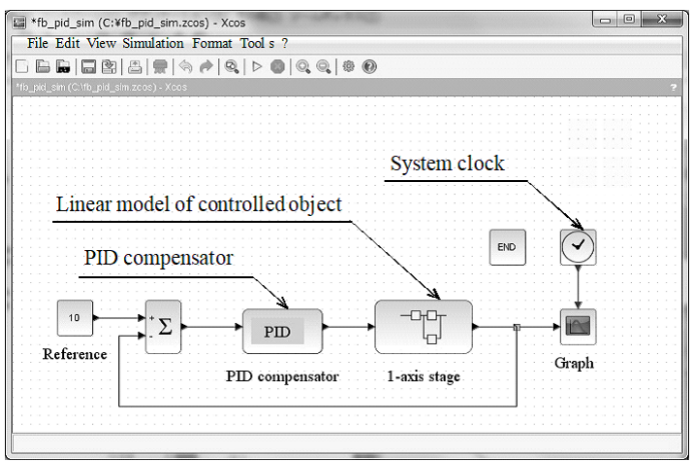

Figure 15: Block diagram of the simulation.

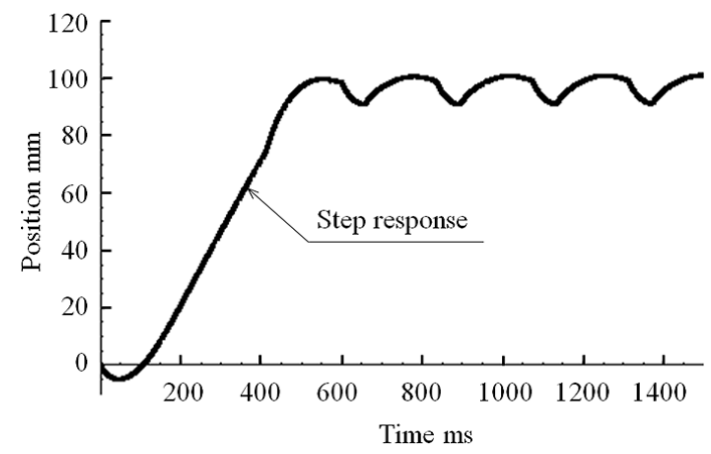

Figure 16: Result of a simulation using Scilab.

accuracy is enough for an experience of beginner. In comparison with a simulation result of Fig. 14, the rise time is equal. Hence, a simulation is valid for a teaching.

Fig. 18 shows a screen shot of HILS that is combining with Scilab and Arduino ${ }^{\circledR}$. An output block and an input block that are connected to Arduino ${ }^{\circledR}$ are drawn on the right end in Fig. 18. An output block drives a DC motor. An input block measures distance. An input port to measure electric current is an optional port of the motor shield. In this way, engineers do not need to make the sketch because Scilab calculates the compensator while accessing true hardware.

3.3 Active Damping System This section describes a result of development of an active damping system. An engineer who attended new curriculum has developed precision control system. Fig. 19 shows structure of an electron beam equipment (After that we call it EB) with an active damping system. An EB carries a sample to be measured into the vacuum chamber. The sample is loaded onto the

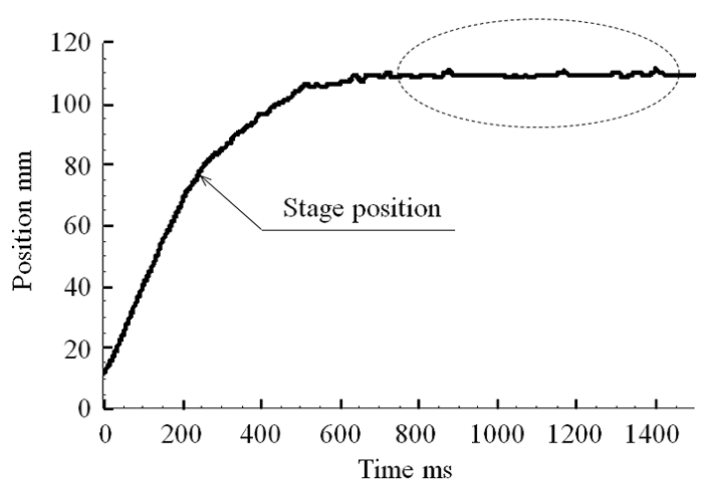

(a) Step movement of $100 \mathrm{~mm}$

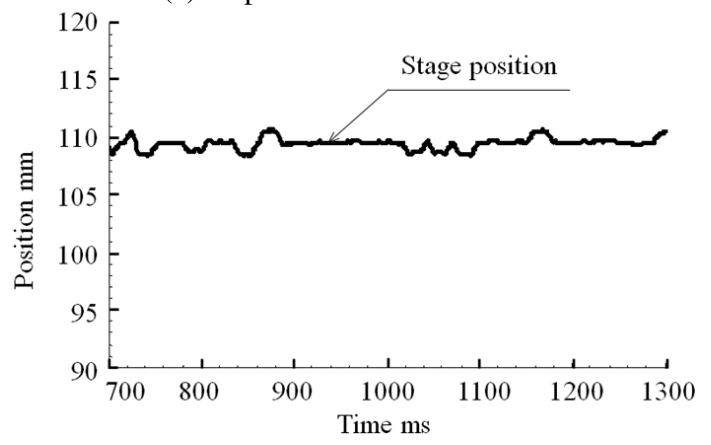

(b) Close-up of steady state

Figure 17: Step response by actual feedback control.

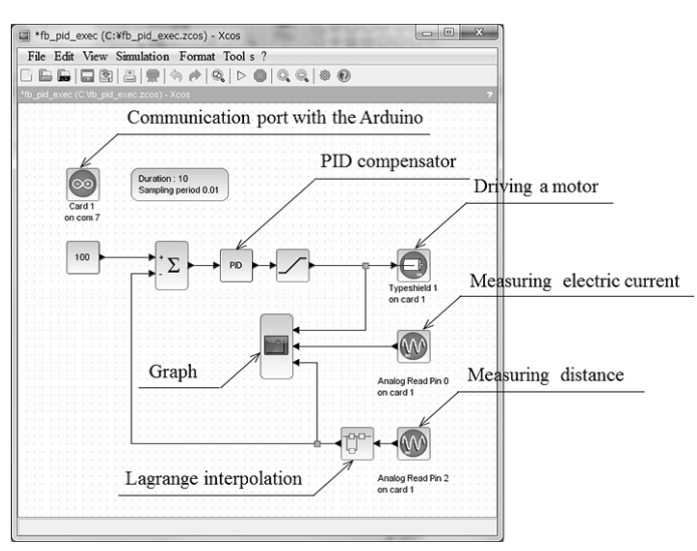

Figure 18: The HILS by Scilab using the Arduino ${ }^{\circledR}$.

stage that is in the vacuum chamber. After that, the sample changes measurement point by movement of the stage. The EB irradiates an electron beam to a circuit pattern formed on the sample. The EB inspects a circuit pattern by an image gotten by scanning the electron beam. An air damper is located under the vacuum chamber, and it controls vibration for high accuracy measurement. By the refinement of the recent circuit pattern, an air damping system is not enough to damp vibration. Accordingly, we have equipped an active vibration system which is constituted by a voice coil motor and an accelerometer.

An engineer has designed a feedback control system. It damps horizontal vibration. Fig. 20 shows both measured frequency characteristics and objective one. An engineer measured vibration of a vacuum chamber in some factories. Then, he has decided an objective characteristics. It was 


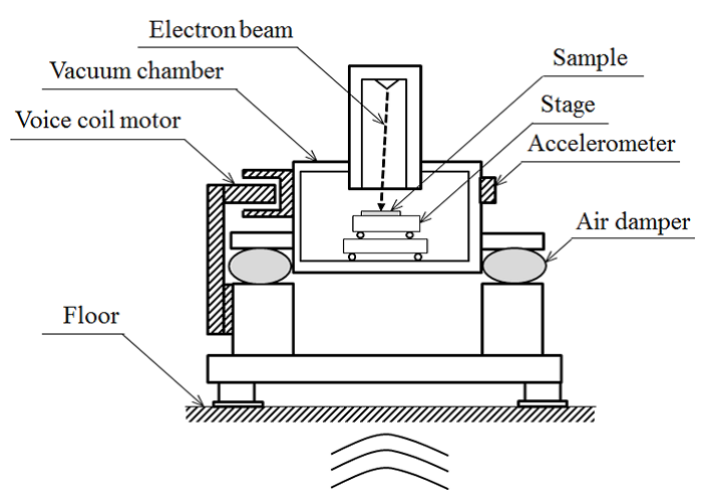

Figure 19: Structure of an electron beam equipemt with active damping system.

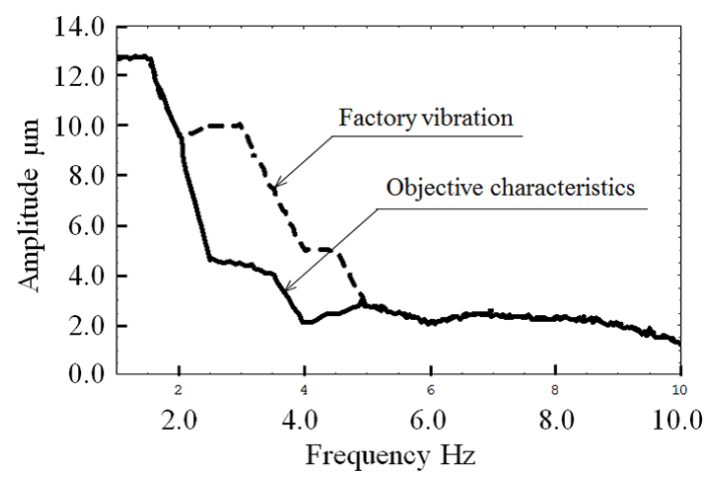

Figure 20: Frequency characteristics.

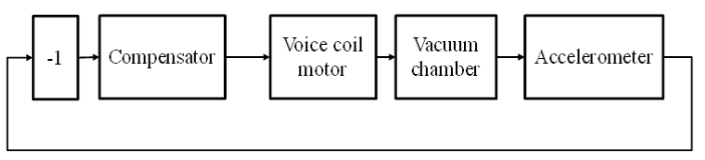

Figure 21: Block diagram of the acivte damping system.

necessary for inspecting highly precise circuit pattern. According to Fig. 20, reduction of the amplitude from 2 to $5 \mathrm{~Hz}$ is necessary. Fig. 21 shows the block diagram of an active damping system. The engineer has designed a closed loop characteristic by objective frequency characteristics. Equation (5) shows a transfer function of closed loop. It forms a band eliminate filter. Here, $\omega_{s}[\mathrm{rad} / \mathrm{s}]$ is central angular frequency of eliminated frequency domain. $\zeta[\mathrm{rad} / \mathrm{s}]$ is bandwidth to be eliminated. $d[-]$ is coefficient of attenuation.

$$
G_{c}(s)=\frac{s^{2}+\zeta s+\omega_{s}^{2}}{s^{2}+d \zeta s+\omega_{s}^{2}}
$$

Fig. 22 shows results of a simulation and an experiment. They are almost corresponding. Fig. 23 shows a result of an experiment that applied the active damping system to a factory. Vibration was reduced by the active damping system. Afterwards, repeatability of measurement accuracy of the LSI line width was measured. The repeatability is very important for inspection equipment. Fig. 24 shows comparison of repeatability of the LSI width. According to Fig. 24, standard deviation when the active damping system worked was $0.0124 \mathrm{~nm}$. Its deviation without the system was 0.0162

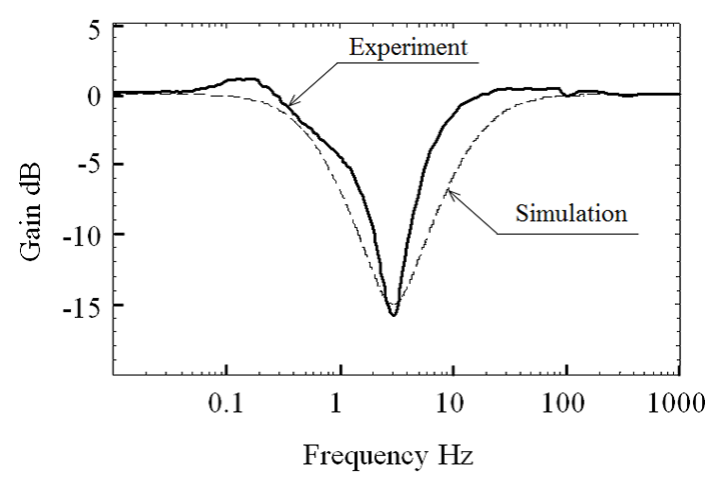

Figure 22: Design of frequency characteristics of the closed loop.

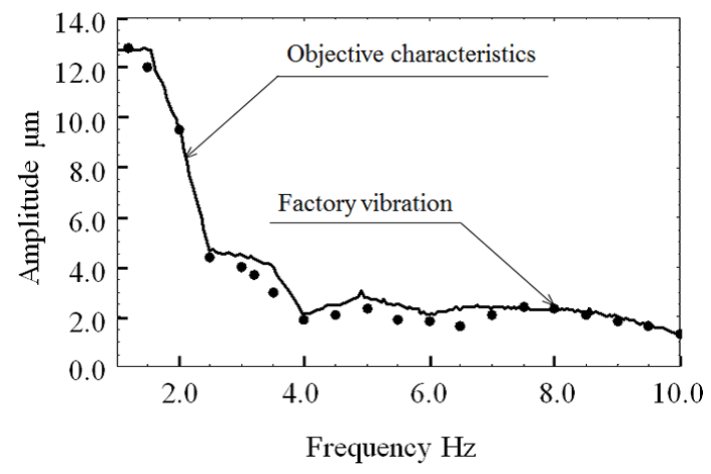

Figure 23: Result of an experiment.

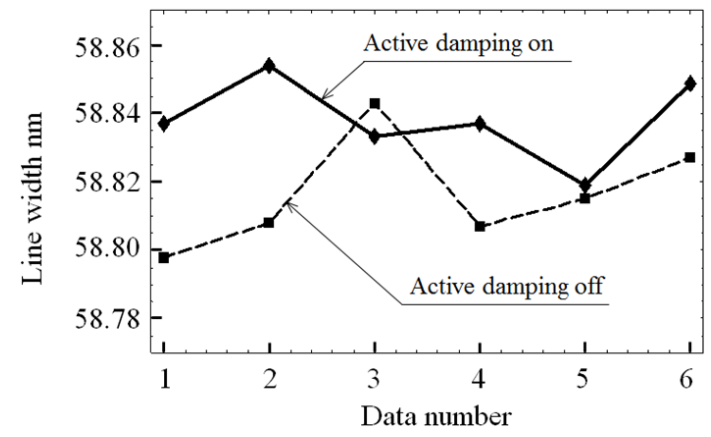

Figure 24: Comparison of repeatability of measurement accuracy of the line width.

$\mathrm{nm}$. Thus, repeatability was improved by the active damping system. It is suitable for measurement of the LSI which has the line width less than $10 \mathrm{~nm}$.

\section{Conclusion}

As a result, the understanding of engineers by new curriculum has improved more than conventional one. After conventional curriculum, engineers in the first group still needed some supports to develop precision apparatuses. However, engineers in the second group did not need any supports, and they could design and implement a compensator for their product by themselves. Although education time has increased for 40 hours from conventional 20 hours to apply new curriculum, effectivity of education was largely improved. According to result of experiment, we 
have reduced development term of commercial products by growth of engineers in short term.

Finally, the result of this study was described.

(a) The teaching material to teach beginner engineer of control engineering was developed. It was the one axis stage consisting of stable and linear elements. In addition, it has used Arduino ${ }^{\circledR}$ which is low cost microcomputer. Cost of the one axis stage was approximately $\$ 200$.

(b) Precise one axis stage was developed. The stage had a sensor measuring position by low cost infrared ray distance sensor. It was linearized and encapsulated by Lagrange interpolation method. Hence, engineers were able to learn control engineering without knowledge of non-linearity.

(c) A teaching method to teach control engineering based on the one axis stage was proposed. The method has improved quality of teaching. Particularly, it is effective for beginner and intermediate engineer. An engineer who participated in the lecture have realized positioning accuracy $\pm 100 \mu \mathrm{m}$.

(d) An engineer has grown by proposed curriculum. He has developed precise active damping system by oneself. An inspection equipment having the system became high accuracy. An amplitude of vibration has reduced from 8 to $4 \mu \mathrm{m}$ at $3 \mathrm{~Hz}$. In addition, the repeatability of the measurement accuracy was improved because standard deviation became $0.0124 \mathrm{~nm}$ from $0.0162 \mathrm{~nm}$.

\section{References}

[1] Kazuhiro Morita, Shinji Wakui, "Study on Precision Temperature Measurement and Control in Vacuum Environment" Journal of the Japan Society for Precision Engineering, vol.82, no.3, pp.266-271, 2016.

[2] Kazuhiro Morita, Shinji Wakui, "Study on Optimization Design Method about Vibration Damping for an Electron Beam System", Journal of the Japan Society for Precision Engineering, vol.82, no.6, pp.583-588, 2016.

[3] Kazuhiro Morita, Shinji Wakui, "Stabilization of the Precision Positioning Stage Working in the Vacuum Environment by Using the Disturbance Observer", Proceedings of the 4th IIAE International Conference on Industrial Application Engineering 2016, pp.263-268, 2016.

[4] Takao Tasaki, Shinichi Watanabe, Yoshihito Shikanai, and Koichi Ozaki, "Development of Hands-on Educational Tool for Control Based on ARCS Model and Emotions", Journal of Robotics ad Mechatronics, vol.23, no.5, pp.676-683, 2011.
[5] Hongtai Cheng, Lina Hao, Zhong Luo, and Fei Wang, "Establishing the Connection between Control Theory Education and Application: An Arduino Based Rapid Control Prototyping Approach", International Journal of Learning and Teaching, vol.2, no.1, pp.67-72, June, 2016.

[6] Massimo Canale and Simone Casale-Brunet, "A Multidisciplinary Approach for Model Predictive Control Education: A Lego Mindstorms NXT-based Framework", International Journal of Control, Automation, and Systems, vol.12, no.5, pp.1030-1039, 2014.

[7] Tasuku Hoshino, Masaki Yamakita and Katsuhisa Furuta, "Control Education Using Pendulum Apparatus", Transaction on Control, Automation, and System Engineering, vol.2 no.2, pp.157-161, 2000.

[8] Seong-Wook Park, "System Development for Education and Design of a Nonlinear Controller with On-Line Algorithm", International Journal of Control, Automation, and Systems, vol.1 no.2, pp.215-221, 2003.

[9] http://www.pid-control.com/products/process/ index.html, PID Co. Ltd. 2017. "Process control experimental apparatus", access date: July 2017.

[10] https://www. leybold-shop.co.uk/technology/ electrical-engineering/control-engineeringand-automation.html, Feedback Instruments Ltd. 2017. "Control engineering and automation", access date: June 2017.

[11] D. Roy Choudhury, Modern Control Engineering, pp.329819,2006

[12] Manabe S., "A low-cost inverted pendulum system for control education", IFAC 3rd Symposium on Adavances in Control Education, pp.21-24, August 1994.

[13] Miguel A. Rubio, Carolina Mañoso Hierro, and Ángel Perez de Madrid y Pablo, "Using Arduino To Enhance Computer Programming Courses In Science And Engineering", Proceedings of EDULEARN13 Conference, pp.5127-51335, July 2013.

[14] Luiz A. Junior, Osvaldo T. Neto, Marli F. Hernandez and Paulo S. Martins and Leonardo L. Roger and Fátima A. Guerra, "A Low-Cost and Simple Arduino-Based Educational Robotics Kit”, Cyber Journals: Multidisciplinary Journals in Science and Technology, Journal of Selected Areas in Robotics and Control (JSRC), vol.3, no.12. pp.1-7, 2013.

[15] André Araújo, David Portugal, Micael S. Couceiro and Rui P. Rocha, "Integrating Arduino-based Educational Mobile Robots in ROS", Proceedings of the 13th International Conference on Mobile Robots and Competitions, pp.8-13, April 2013.

[16] Ángeles Hoyo, José Luis Guzmán and José Carlos Moreno, "Teaching Control Engineering Concepts using Open Source tools on a Raspberry Pi board", IFAC-Papers Online, vol.48, no.29, pp.99-104, 2015

[17] Xiaoyang Zhong and Yao Liang, "Raspberry Pi: An Effective Vehicle in Teaching the Internet of Things in Computer Science and Engineering", eletctronics, vol.5, no.56, 2016. 
[18] https://www.arduino.cc/, Arduino AG. 2017. "Arduino.”, access date: June 2017.

[19] http://www.scilab.org/, Scilab Enterprises. 2016. "Scilab.", access date: December 2016.

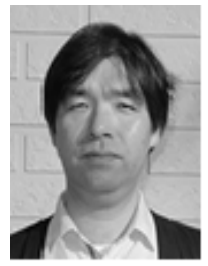

Morita Kazuhiro (Member) is senior engineer of Hitachi High Technologies Corporation at Ibaraki, Japan. He is lecturer of Electronic and Computer Engineering at National Institute of Technology, Ibaraki College in Ibaraki, Japan. $\mathrm{He}$ is authorized professional engineer in Japan. His research interests include precision positionmember of IIAE. ing, damping control and its applications. He is

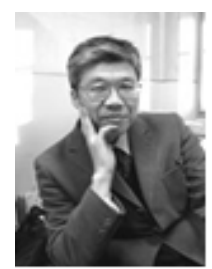

Wakui Shinji (Non-member) is professor of the Institute of Engineering at Tokyo University of Agriculture and Technology in Tokyo, Japan. He received his Ph.D. from Kanazawa University in 1993. His research interests precision positioning and its applications. 